Tema: Gestão Sistêmica

\title{
OTIMIZAÇÃO DE ENSAIOS LABORATORIAIS DE PRODUTOS PARA FINS ELÉTRICOS NA CSN COM USO DE FERRAMENTAS LEAN SIX SIGMA*
}

\author{
Kleidon Rodrigues de Almeida ${ }^{1}$ \\ Mariana Corrêa Assis² \\ Luiz Marques Barbosa ${ }^{3}$ \\ Júlio Cesar Lopes da Silva
}

\section{Resumo}

O presente projeto descreve um trabalho de otimização dos ensaios laboratoriais de liberação do produto para fins elétricos na CSN (Companhia Siderúrgica Nacional), sendo tema de um projeto Lean Six Sigma. O foco do projeto foi otimizar os ensaios de epstein, tração e dureza, reduzindo o Lead Time de liberação dos produtos para fins elétricos e a quantidade de ensaios realizados. Para a realização deste trabalho, fez-se o uso de ferramentas e métodos Lean Six Sigma, permitindo a busca dos resultados de maneira sistêmica, superando as metas estabelecidas, gerando uma maior competitividade à empresa no mercado. Obteve-se com este projeto uma forte redução do Lead Time e da quantidade dos ensaios laboratoriais dentro de um prazo estabelecido, permitindo uma liberação para faturamento no mesmo dia de produção em $80 \%$ da produção deste produto.

Palavras-chave: Lean six sigma; Otimização; Ensaio de Epstein; Tração; Dureza; Aços para fins elétricos.

\section{OPTIMIZATION OF LABORATORY TESTS ON ELECTRIC GRADE STEEL AT CSN USING METHODS OF LEAN SIX SIGMA}

\begin{abstract}
This project describes the optimization of laboratory testing of electric grade steel, being the subject of a Lean Six Sigma project. The purpose of this project was to optimize the test laboratory for epstein, traction hardness and reduce the Lead Time of the tests, in addition to reducing the number of tests performed. Lean Six Sigma methods were used, allowing the search results in a systemic way surpassing the set targets, generating greater competitiveness in the enterprise market. Obtained in this work a significant reduction of Lead Time and quantity of laboratory tests within a specified period, allowing a release for billing on the same day of production in $80 \%$ of the production of this product.
\end{abstract}

Keywords: Lean six sigma; Optimization; Epstein method; Tensile test; Hardness Test; Electric grade steel.

1 Engenheiro de Produção Mecânica, Engenheiro de Desenvolvimento, Gerência Geral de Processos Siderúrgicos, Companhia Siderúrgica Nacional (CSN), Volta Redonda, Rio de Janeiro, Brasil.

2 Engenheiro Metalurgista, Engenheiro de Desenvolvimento, Gerência de Desempenho Operacional, CSN, Volta Redonda, Rio de Janeiro, Brasil.

3 Técnico em Metalurgia, Supervisor de Laboratório de Qualidade de Produtos Laminados, Gerência Geral de Processos Siderúrgicos, CSN, Volta Redonda, Rio de Janeiro, Brasil.

4 Técnico em Metalurgia, Técnico de Desenvolvimento, Gerência Geral de Desenvolvimento de Produtos, CSN, Volta Redonda, Rio de Janeiro, Brasil.

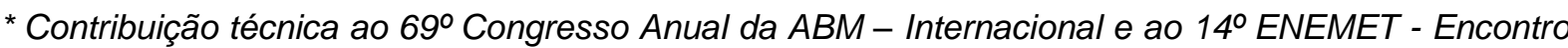
Nacional de Estudantes de Engenharia Metalúrgica, de Materiais e de Minas, 21 a 25 de julho de 2014, São Paulo, SP, Brasil.
} 


\section{INTRODUÇÃO}

De maneira geral, todo o material usado no processo de manufatura de produtos implica em custos diretos ou indiretos para o cliente. Baseado nisto, surge à necessidade de se buscar reduções de custos ao longo da cadeia produtiva, o que pode ser um diferencial competitivo no mercado de produtos siderúrgicos.

O Lean Manufacturing é uma iniciativa que busca eliminar desperdícios, isto é, eliminar o que não tem valor para o cliente e imprimir velocidade à empresa.

Neste trabalho, é mostrado o uso da metodologia Lean Six Sigma com o objetivo de reduzir o Lead Time do ensaio epstein e otimizar os demais ensaios feitos no produto para fins elétricos.

Este trabalho foi usado como projeto para obtenção de certificação Green Belt. Um Green Belt é uma pessoa com conhecimento teórico e prático da metodologia Seis Sigma, incluindo ferramentas estatísticas, de qualidade e técnicas Lean, além de se envolver em projetos de melhoria que visem ganhos expressivos.

Os "aços elétricos" são usados por possuírem uma qualidade de amplificar em milhares de vezes um campo magnético externamente aplicado. São normalmente usados na geração, transmissão e utilização da energia elétrica. Seu emprego é muito amplo, sendo aplicados nos núcleos de geradores e motores elétricos (de pequeno a grande porte), reatores para sistemas de iluminação, medidores de energia, motores para compressores herméticos de geladeiras, freezers e arcondicionado, entre outros.

O ensaio de epstein é usado para quantificar a perda magnética de um aço para fins elétricos antes do seu uso na fabricação de motores. Na CSN, este ensaio possuía um Lead Time médio de 7 dia. Por ser considerado como um alto tempo para a realização das análises, o Lead Time deste ensaio foi identificado como um problema a ser tratado.

Com a implantação das recomendações sugeridas ao término do trabalho, foi possível constatar uma expressiva redução do Lead Time do ensaio epstein, bem como a otimização deste ensaio e dos demais envolvidos na caracterização do produto para fins elétricos.

\section{MATERIAIS E MÉTODOS}

A última etapa de transformação de um aço para fins elétricos ocorre em uma linha de Recozimento Contínuo, sendo este, um tratamento térmico que tem como finalidade reestabelecer as propriedades mecânicas alteradas durante a laminação a frio. O Recozimento também modifica as características elétricas e magnéticas, dando ao produto para fins elétricos uma maior eficiência elétrica (menor perda).

Após o processo de Recozimento Contínuo, o material passa por uma série de ensaios laboratoriais, a fim de que sejam garantidas algumas características (mecânicas e elétricas). Dentre as análises feitas no aço, destacam-se: o ensaio de tração e dureza (medem o comportamento mecânico) e o ensaio de epstein (quantifica a perda magnética/elétrica).

No início do projeto, o cenário de demanda do mercado para aços de fins elétricos na CSN era de aumento ao longo do tempo, conforme pode ser observado na figura 1.

\footnotetext{
* Contribuição técnica ao $69^{\circ}$ Congresso Anual da ABM - Internacional e ao 14ํㅡㄹ ENEMET - Encontro Nacional de Estudantes de Engenharia Metalúrgica, de Materiais e de Minas, 21 a 25 de julho de 2014, São Paulo, SP, Brasil.
} 

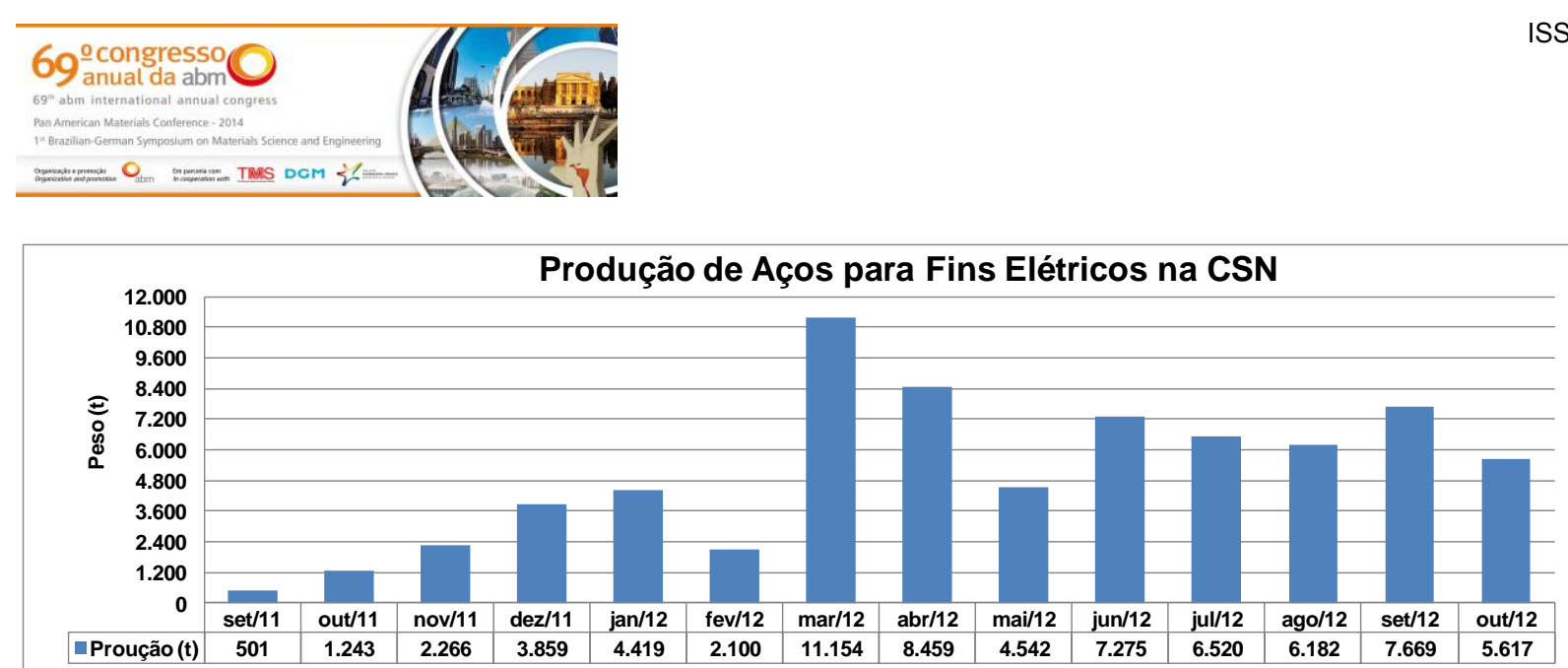

Figura 1. Produção de aços para fins elétricos na CSN

A quantidade de ensaios epstein para análise das perdas magnéticas subia na mesma proporção do aumento de produção. Portanto, identificou-se uma necessidade de melhoria quanto ao Lead Time do ensaio epstein, uma vez que este demandava um tempo médio de 7 dias para ser realizado. Durante a realização dos ensaios, o material (as bobinas) não pode ser liberado para faturamento e entrega. Contudo, definiu-se o problema: alto tempo (Lead Time) de análise do ensaio epstein.

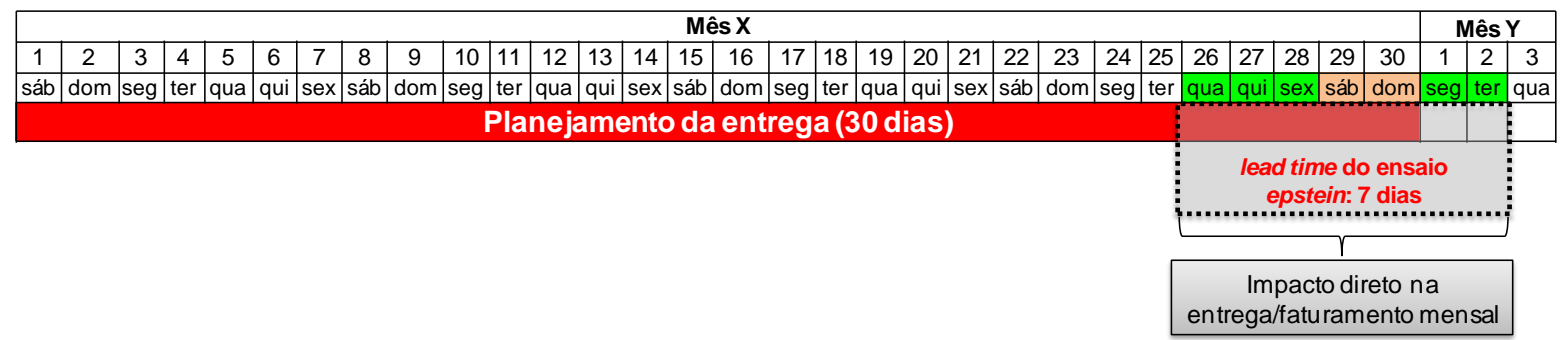

Figura 2. Demonstração de impacto do Lead Time na entrega de produtos para fins elétricos

A figura 2 mostra o impacto que o Lead Time do ensaio epstein causa na entrega de produtos para fins elétricos, principalmente se a produção deste produto ocorrer a partir do dia 26 do mês. Neste caso, o material só poderá ser liberado para entrega/faturamento a partir do dia 02 do mês seguinte, devido à realização ao tempo necessário para realização do ensaio de epstein.

\footnotetext{
* Contribuição técnica ao 69ำ Congresso Anual da ABM - Internacional e ao 14ํㅡㄹ ENEMET - Encontro Nacional de Estudantes de Engenharia Metalúrgica, de Materiais e de Minas, 21 a 25 de julho de 2014, São Paulo, SP, Brasil.
} 


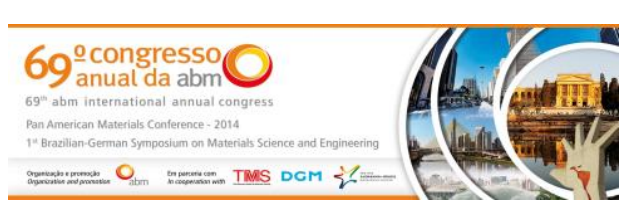

Brainstorming - Redução do lead time do ensaio de epstein

$==>$ Amostras não retiradas na linha de produção

$==>$ Demora no recolhimento das amostras na linha de produção

$==>$ Alto tempo na elaboração da Ordem de Servoço para o laboratório da

Pesquisa

==> Horário inadequado de envio das amostras ao laboratório da Pesquisa

$==>$ Demora no recebimento das amostras no laboratório da Pesquisa

$==>$ Guilhotinas com defeitos mecânicos (laboratório da Pesquisa)

$==>$ Dificuldade para cortar amostras (dureza alta)

==> Falta de prioridade para execução de tratamento térmico e/ou ensaio de epstein

$==>$ Forno com problemas (demora no tratamento térmico)

$==>$ Longo tempo para lançamento dos valores de perdas elétricas no sistema

PAE (disponibilidade dos resultados)

$==>$ Longo tempo para lançamento dos valores de perdas elétricas, dureza e tração no SAP (disponibilidade dos resultados)

Figura 3. Brainstorming para a redução do Lead Time do ensaio de epstein

Uma vez definido o problema, fez-se um Brainstomirg (figura 3) e consequentemente um Diagrama de Causa e Efeito (figura 4), o que permitiu estruturar hierarquicamente as causas do problema.

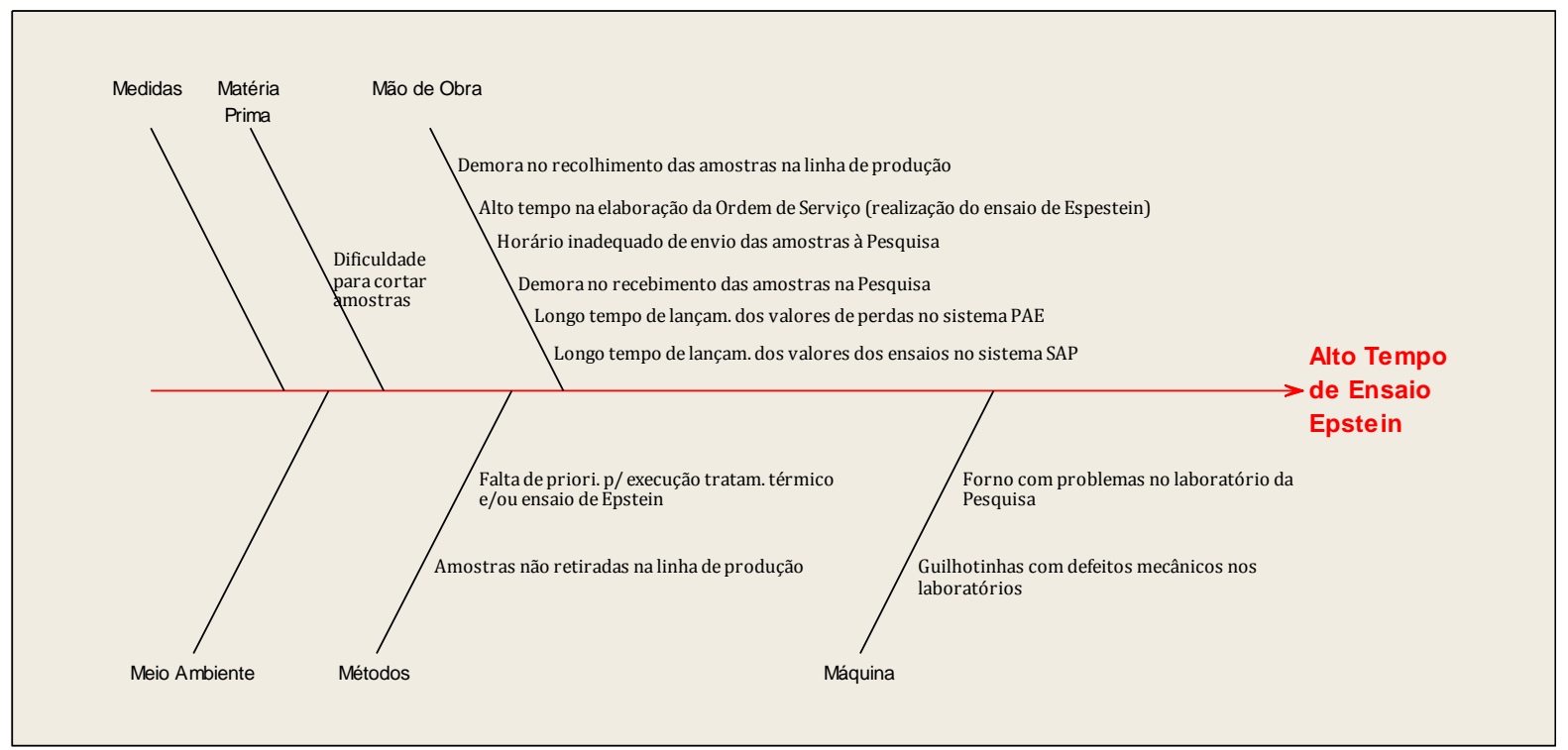

Figura 4. Diagrama de Causa e Efeito referente ao alto tempo de ensaio epstein

De acordo com a figura 4, a maioria das causas potenciais estavam relacionadas à mão de obra emprega na realização do ensaio de epstein.

O DMAIC (Define, Measure, Analyze, Improve e Control) é um método estruturado para o alcance de metas utilizado na metodologia Seis Sigmas, que fomenta a busca de bons resultados.

O método DMAIC foi aplicado com o auxílio do Mapa de Raciocínio (ver figura 5), que por sua vez, trata-se de uma ferramenta usada para estruturar o projeto, é uma documentação progressiva na forma de raciocínio durante a execução de um projeto. O Mapa de Raciocínio ajuda a descrever o problema, as metas do projeto, as questões às quais a equipe precisou responder durante o desenvolvimento do

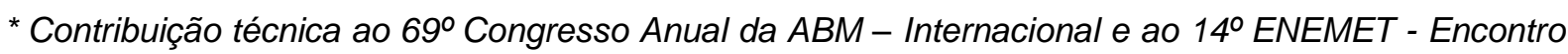
Nacional de Estudantes de Engenharia Metalúrgica, de Materiais e de Minas, 21 a 25 de julho de 2014, São Paulo, SP, Brasil.
} 


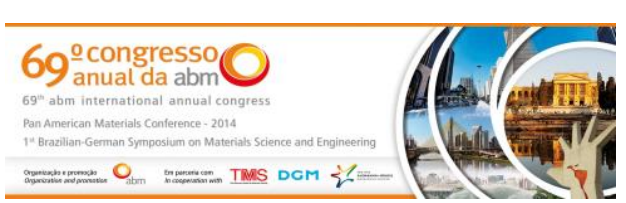

projeto, o que foi feito para responder às questões, respostas às questões, novas questões, novos passos, novas respostas.

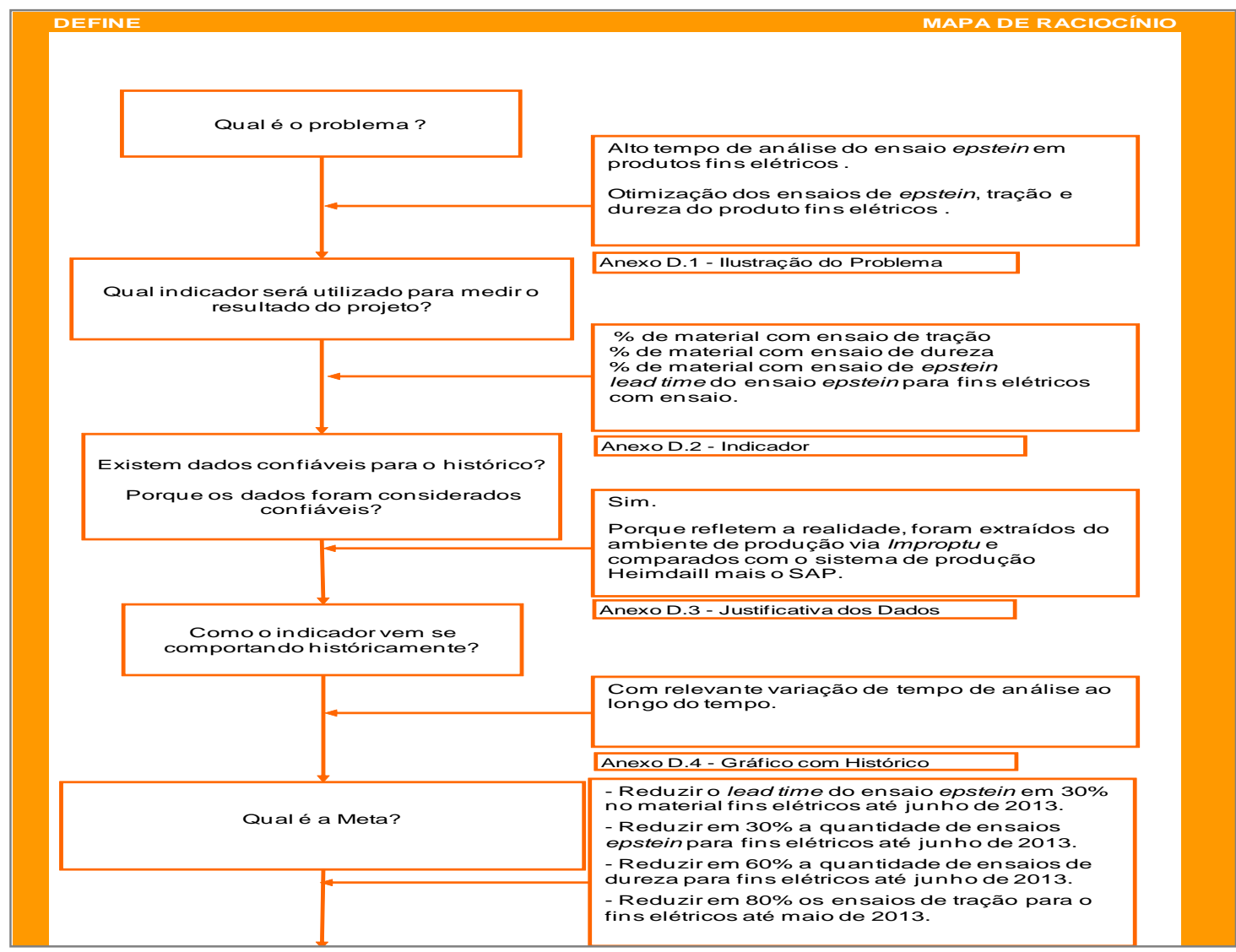

Figura 5. Mapa de Raciocínio usado na fase Define.

O Mapa de Raciocínio favorece contribuições (novos conhecimentos e ideias) de pessoas que não fazem parte da equipe responsável pelo trabalho, já que o entendimento do projeto fica facilitado.

Uma importante análise feita foi conhecer quais ensaios as demais empresas que produzem aços para fins elétricos faziam em seus produtos dentro das usinas siderúrgicas, para tal, fez um quadro comparativo (benchmarking) de cada produto, que pode ser visto na tabela 1.

Tabela 1. Quadro comparativo dos ensaios para aços fins elétricos

\begin{tabular}{|c|c|c|c|c|}
\hline \multirow{2}{*}{ Empresa } & Eficiência elétrica & Ensaio de tração & Ensaio de dureza & Ensaio de epstein \\
\hline \multirow{2}{*}{ CSN } & Baixa & $X$ & $X$ & $X$ \\
\cline { 2 - 5 } & Média & $X$ & $X$ & $X$ \\
\hline \multirow{2}{*}{ Concorrente A } & Baixa & X & & \\
\cline { 2 - 5 } Concorrente B & Média & Baixa & X & Não produz \\
\cline { 2 - 5 } & Média & $X$ & & $X$ \\
\hline
\end{tabular}

Além do alto tempo para realização dos ensaios epstein, percebeu-se (após análise da tabela 1) que a CSN estava fazendo uma quantidade de ensaios maior que os demais fornecedores de produtos para fins elétricos. Algumas questões sugiram: É necessária a realização de tantos ensaios? Quais ensaios poderemos otimizar? Etc. O próximo passo foi definir as metas, conforme segue:

- Reduzir o Lead Time do ensaio epstein em 30\% até junho de 2013;

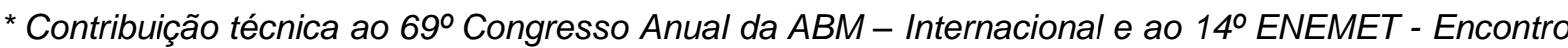
Nacional de Estudantes de Engenharia Metalúrgica, de Materiais e de Minas, 21 a 25 de julho de 2014, São Paulo, SP, Brasil.
} 
Com o intuito de elaborar um plano bem estruturado para melhorar a produtividade, reduzir os desperdícios e o Lead Time dos ensaios de laboratório, foi criado um Mapa de Fluxo de Valor. Permitindo separar aquilo que agregava valor aos olhos do cliente e aquilo que não agregava valor. Entende-se aqui por fluxo de valor 0 conjunto de todas as atividades que agregam valor desde a obtenção de matéria prima até a entrega do produto ao consumidor final. Nas figuras 7,8 e 9 ver-se a 0 uso desta ferramenta para o ensaio de tração, dureza e epstein respectivamente.

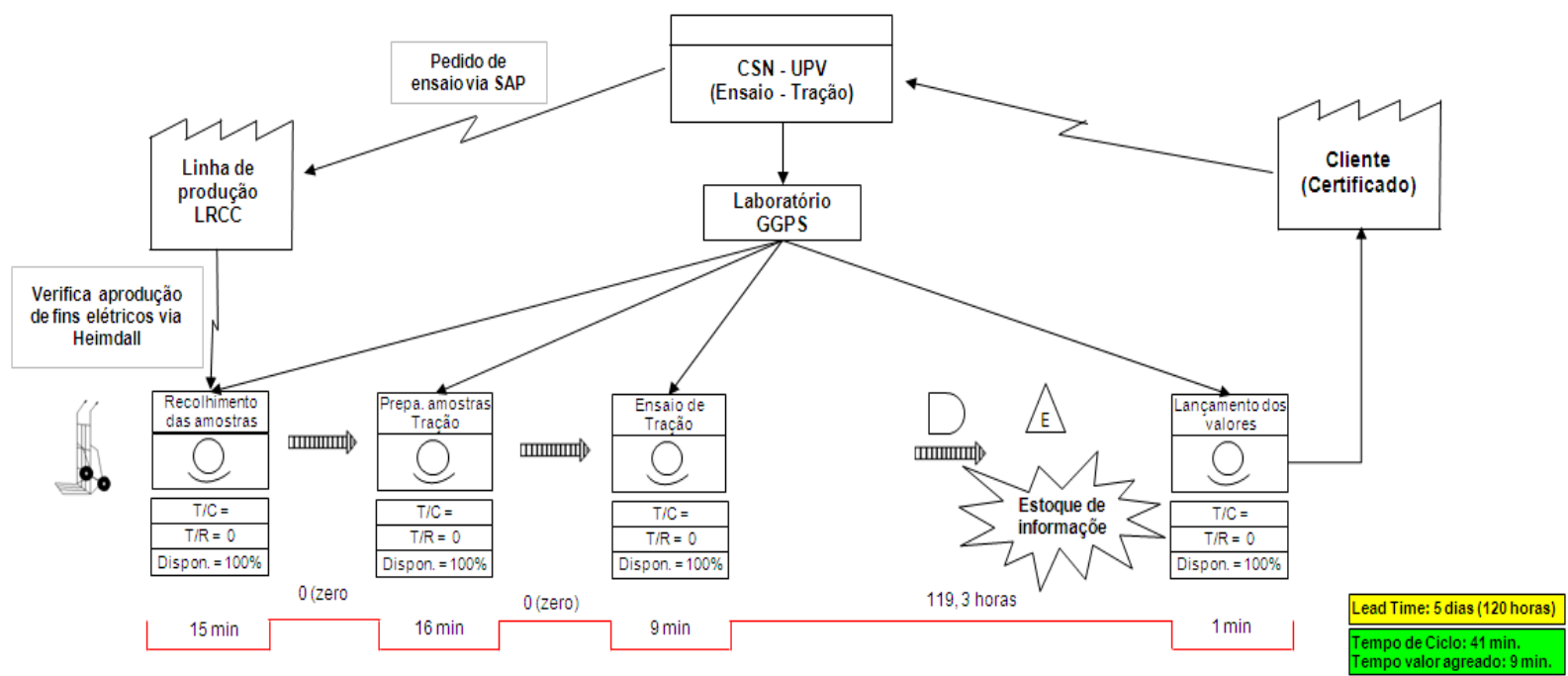

Figura 7. Mapa de Fluxo de Valor do ensaio de tração

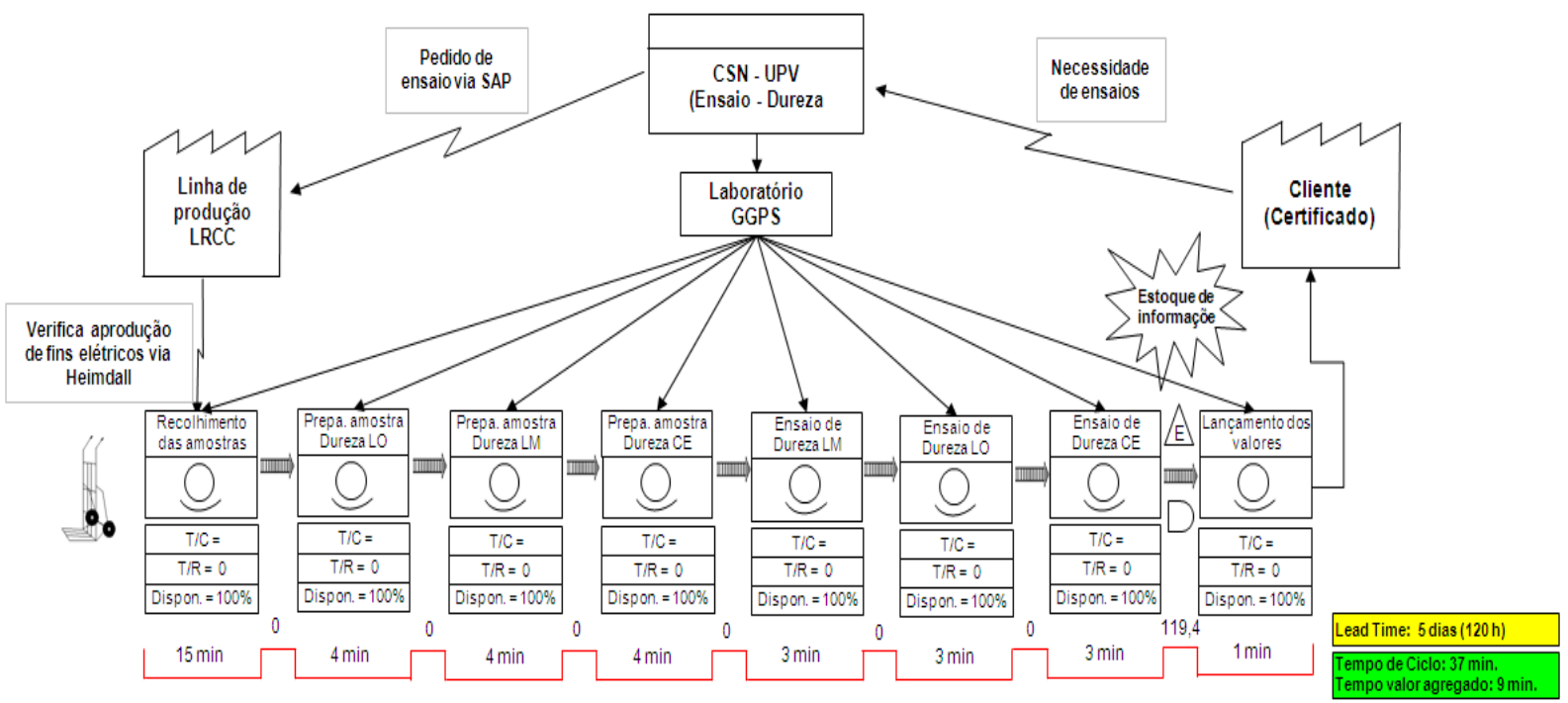

Figura 8. Mapa de Fluxo de Valor do ensaio de dureza

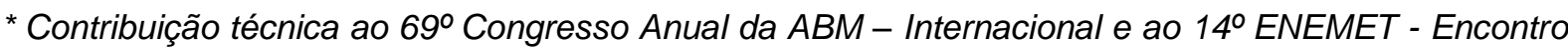
Nacional de Estudantes de Engenharia Metalúrgica, de Materiais e de Minas, 21 a 25 de julho de 2014, São Paulo, SP, Brasil. 


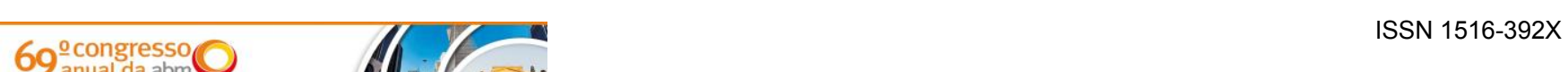

DOM

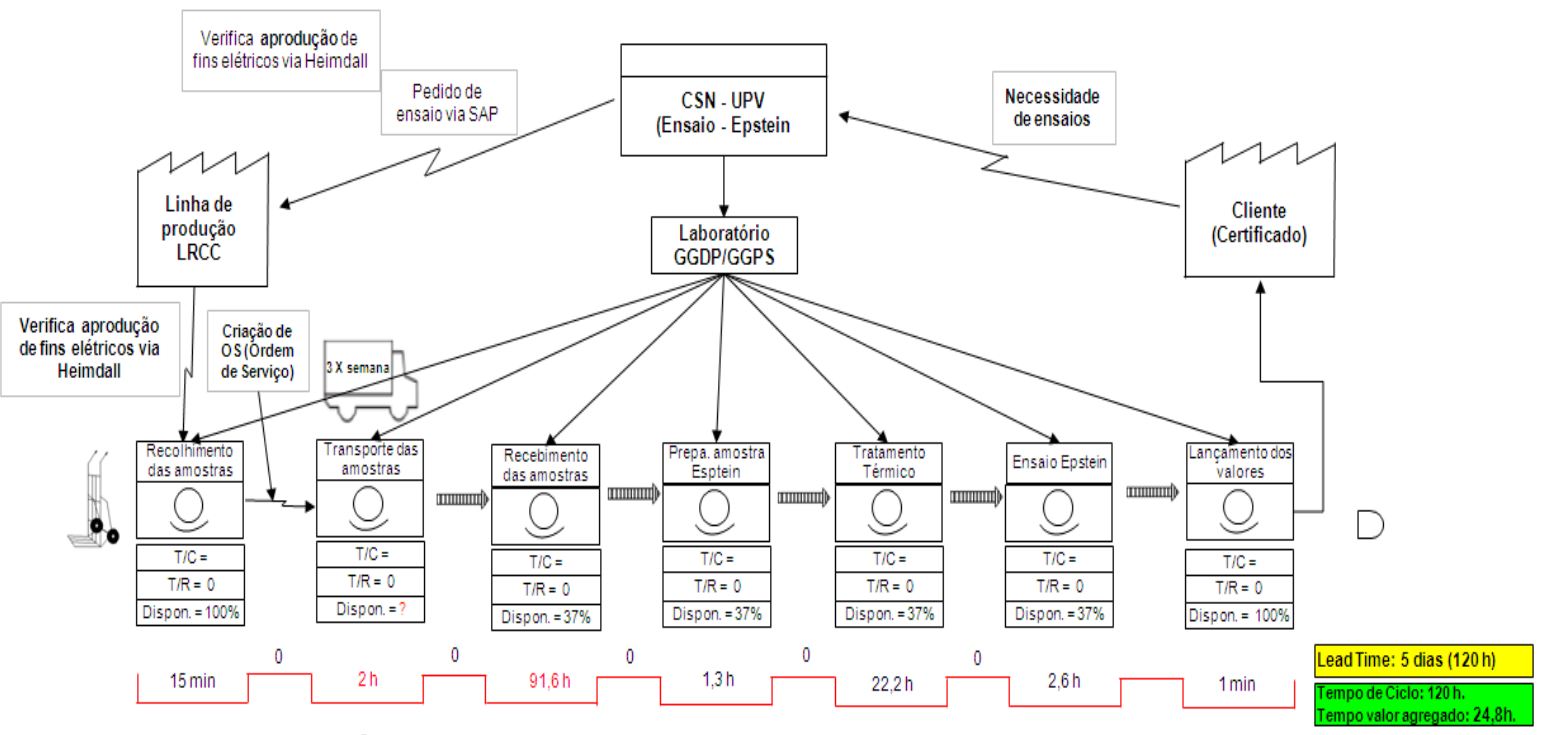

Figura 9. Mapa de Fluxo de Valor do ensaio de epstein

Apesar de o ensaio de tração ser realizado em 41 minutos (figura 7) e o de dureza em 37 minutos (figura 8), ambos tinham o valor lançado no sistema de controle de ensaios após a realização do ensaio de epstein (figura 9), portanto, os tempos de ensaio eram acrescidos em função da espera para finalização do ensaio de epstein, que por sua vez possuía um Lead Time de 120 minutos. Portanto, o ensaio de epstein foi apontado como gargalo, por ser o que demandava um maior tempo para a realização, impedindo assim a liberação do material para faturamento/entrega.

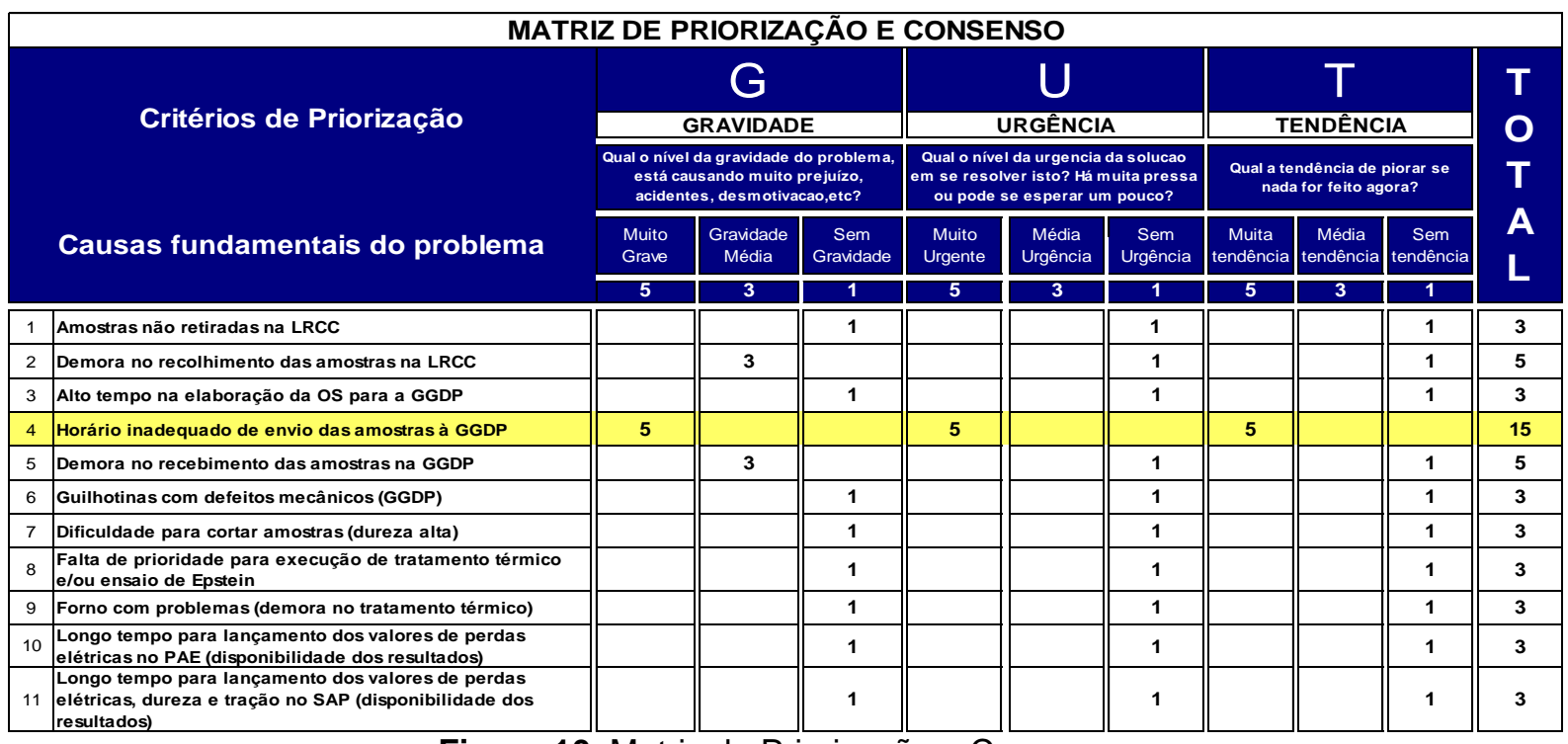

Figura 10. Matriz de Priorização e Consenso

A figura 10 mostra uma Matriz GUT, esta ferramenta permitiu a avaliar de forma quantitativa o problema, tornando possível priorizar as ações corretivas e preventivas e otimizar os ensaios, minimizando o tempo gasto na execução. A primeira atividade na montagem da Matriz GUT, foi listar todos os problemas relacionados às atividades. Em seguida foi atribuída uma nota para cada problema listado, dentro dos três aspectos principais: Gravidade, Urgência e Tendência. Cada problema analisado recebeu uma pontuação de 1 a 5 em cada uma das características. Depois de atribuída a pontuação, multiplicou-se GxUxT chegando a

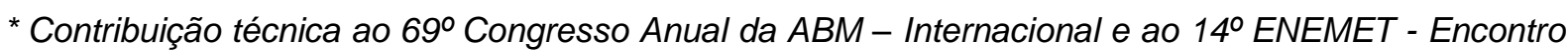
Nacional de Estudantes de Engenharia Metalúrgica, de Materiais e de Minas, 21 a 25 de julho de 2014, São Paulo, SP, Brasil. 


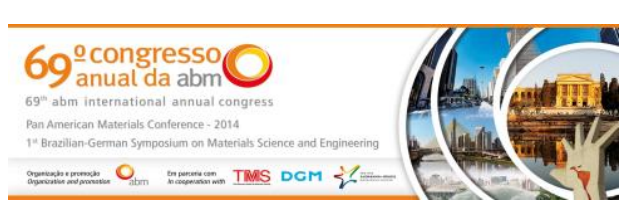

um resultado, definindo a prioridade de acordo com os pontos obtidos. Esta ferramenta mostrou que deveríamos atuar no horário de envio das amostras para análise.

O ensaio de epstein é realizado apenas em dias úteis e em horário de 07:30h às 17:15h. Havendo a necessidade de explorar o período útil, ou seja, se fosse enviada uma amostra após 17:00h, esta iniciaria a preparação para análise apenas no dia seguinte ou dois dias após, se a entrega ocorresse na sexta-feira.

Para otimizar a quantidade de ensaios de dureza, percebeu-se que havia uma baixa variação de resultados quando comparados as medições ao longo da largura da bobina. O padrão de ensaio preconizava medição nas duas bordas da bobina (LM Lado Motor e LO - Lado Operador) e no centro da largura. Uma análise estatística foi realizada a fim de comparar os resultados destas três regiões. Um gráfico de Box Plot foi usado, podendo ser visto na figura 11. Este demonstra uma baixa variação de dureza entre as regiões analisadas.

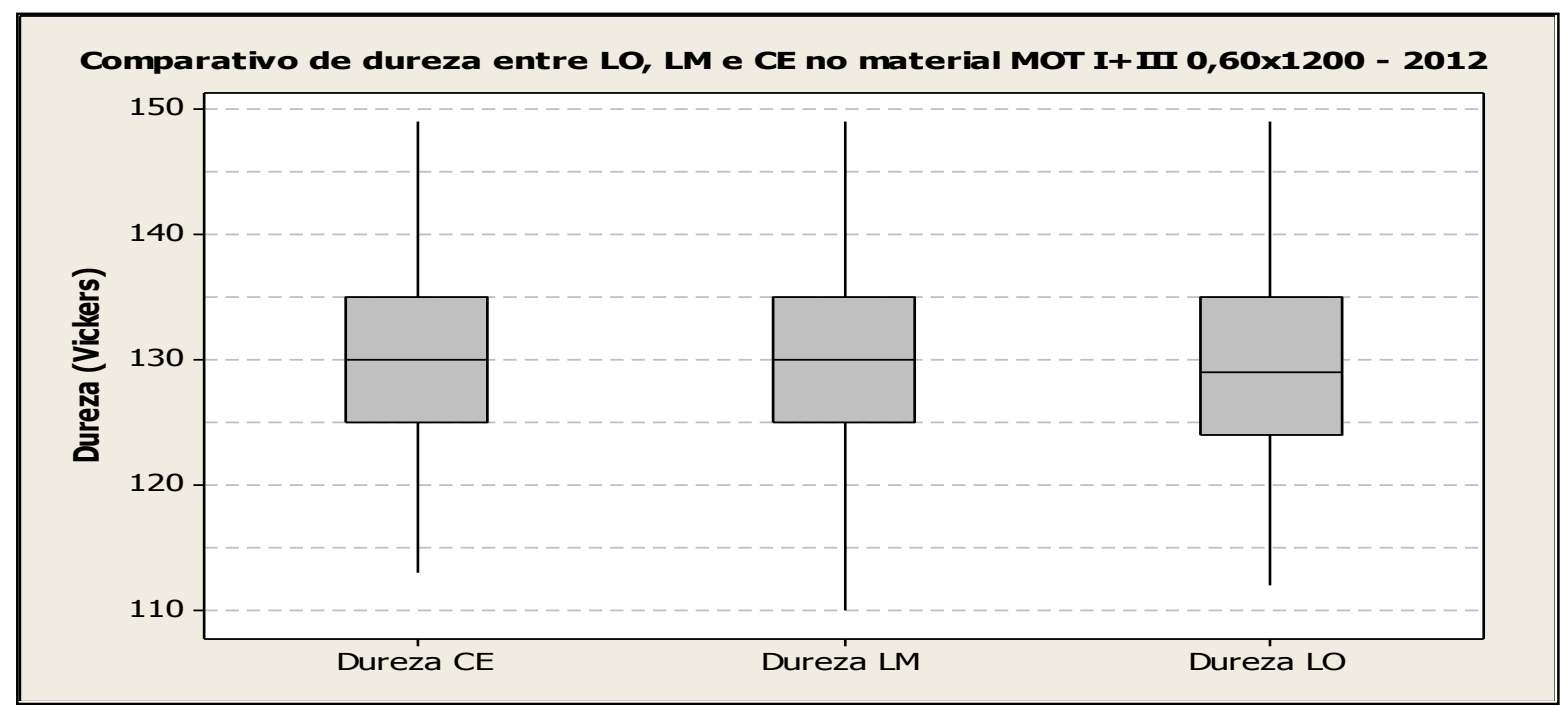

Figura 11. Comparativo de dureza entre os lados (LO e LM) e centro da bobina

A partir das soluções propostas (tabela 3), foram priorizadas a ações a serem implementadas (tabela 4). Em seguinte foram medidos os riscos de cada ação (tabelas 5), chegando a elaboração de um 5W2H (tabela 6), ficando estabelecido o que seria efetivamente feito, o responsável, em qual período de tempo e quanto custaria cada atividade/ação à empresa.

\footnotetext{
* Contribuição técnica ao $69^{\circ}$ Congresso Anual da ABM - Internacional e ao 14ํㅡㄹ ENEMET - Encontro Nacional de Estudantes de Engenharia Metalúrgica, de Materiais e de Minas, 21 a 25 de julho de 2014, São Paulo, SP, Brasil.
} 
Tabela 3. Soluções propostas

\begin{tabular}{|c|c|c|c|}
\hline $\begin{array}{l}\text { Alto tempo } \\
\text { do Ensaio } \\
\text { Epstein }\end{array}$ & $\left|\begin{array}{c}\text { Otimização dos } \\
\text { ensaios de } \\
\text { Dureza e Tração }\end{array}\right|$ & $\begin{array}{c}\text { CAUSA } \\
\text { FUNDAMENTAL }\end{array}$ & SOLUÇÕES PROPOSTAS \\
\hline \multirow[t]{3}{*}{$\times$} & $\times$ & $\begin{array}{l}\text { Horário inadequado } \\
\text { para coleta das } \\
\text { amostras no LAB da } \\
\text { GGPS para transportar } \\
\text { à GGDP }\end{array}$ & $\begin{array}{l}\text { Eleger um respon sável na GLP para monitorar o material fins elétricos } \\
\begin{array}{l}\text { Verificar o tempo necessário para o processo de preparação das amostras no } \\
\text { laboratório mecânico da GGDP }\end{array} \\
\text { Avaliar a disponibilidade do tran sporte de amostras (se atende outros setores) } \\
\begin{array}{l}\text { Criar check list para monitoramento dos tempos dos ensaios envolvendo os aços fins } \\
\text { elétricos }\end{array} \\
\text { Definir um horário limite para coleta das amostra (a serem enviadas à GGDP) } \\
\begin{array}{l}\text { Comparar ferramentas para preparação das amostras no laboratório LQ/LF-LZ e } \\
\text { GGDP }\end{array} \\
\begin{array}{l}\text { Treinar equipes da operação do laboratório LQ/LF-LZ para preparação de amostras e } \\
\text { tratamento térmico na GGDP }\end{array} \\
\text { Avaliar a possibilidade de envio de amostras preparadas à GGDP } \\
\text { Colocar na regra de programação o lead time do ensaio de Epstein } \\
\text { Criar indicador de medição do lead time real semanalmente e mensalmente } \\
\text { Criar indicador de material aguardando ensaio } \\
\text { Liberar material aguardando ensaio de Epstein antes do final do ensaio (apenas no } \\
\text { final do mês) }\end{array}$ \\
\hline & $\times$ & $\begin{array}{l}\text { Ensaio de tração } \\
\text { desnecessário }\end{array}$ & \begin{tabular}{|l|} 
Estudar as normas de garantias, MPA e padrões internos \\
Consultar clientes quanto à necessidade de ensaio de tração \\
Conhecer qual o tipo de ensaio/processo o material é submetido nos clientes \\
Eliminar en saios de tração para clientes que não solicitem \\
\end{tabular} \\
\hline & $\times$ & $\begin{array}{l}\text { Boa "capabilidade" de } \\
\text { dureza nos aços fins } \\
\text { elétricos }\end{array}$ & \begin{tabular}{|l|} 
Fazer levantamento de dados para análise de dureza LM, CE e LO \\
Estudar as normas de garantias, MPA e padrões internos \\
Consultar clientes quanto à necessidade de ensaio de dureza \\
Conhecer qual o tipo de en saio/processo o material é submetido nos clientes \\
Passar a usar du reza apenas do região do centro (CE) da bobina \\
\end{tabular} \\
\hline
\end{tabular}

Tabela 4. Soluções priorizadas

\begin{tabular}{|c|c|c|c|}
\hline $\begin{array}{l}\text { Alto tempo do } \\
\text { Ensaio } \\
\text { Epstein }\end{array}$ & $\begin{array}{l}\text { 0 Otimização dos } \\
\text { ensaios de Dureza } \\
\text { e Tração }\end{array}$ & $\begin{array}{c}\text { CAUSA } \\
\text { FUNDAMENTAL }\end{array}$ & SOLUÇÕES PRIORIZADAS \\
\hline$x$ & & $\begin{array}{l}\text { Horário inadequado } \\
\text { para coleta das } \\
\text { amostras no LAB da } \\
\text { GGPS para transportar } \\
\text { à GGDP }\end{array}$ & \begin{tabular}{|l} 
Eleger um responsável na GLP para monitorar o material fins elétricos \\
Avaliar a disponibilidade do transporte de amostras (se atende outros setores) \\
Criar check list para monitoramento dos tempos dos ensaios envolvendo os aços \\
fins elétricos \\
Definir um horário limite para coleta das amostra (a serem enviadas à GGDP) \\
Criar indicador de medição do lead time real semanalmente e mensalmente \\
Criar indicador de material aguardando ensaio \\
Liberar material aguardando ensaio de Epstein antes do final do ensaio (apenas \\
no final do mês)
\end{tabular} \\
\hline & x & $\begin{array}{l}\text { Ensaio de tração } \\
\text { desnecessário }\end{array}$ & \begin{tabular}{|l} 
Estudar as normas de garantias, MPA e padrões internos \\
Consultar clientes quanto à necessidade de ensaio de tração \\
Conhecer qual o tipo de ensaio/processo o material é submetido nos clientes \\
Eliminar ensaios de tração para clientes que não solicitem
\end{tabular} \\
\hline & $x$ & $\begin{array}{l}\text { Boa "capabilidade" de } \\
\text { dureza nos aços fins } \\
\text { elétricos }\end{array}$ & \begin{tabular}{|l|} 
Fazer levantamento de dados para análise de dureza LM, CE e LO \\
Estudar as normas de garantias, MPA e padrões internos \\
Consultar clientes quanto à necessidade de ensaio de dureza \\
Conhecer qual o tipo de ensaio/processo o material é submetido nos clientes \\
Passar a usar dureza apenas do região do centro (CE) da bobina \\
\end{tabular} \\
\hline
\end{tabular}

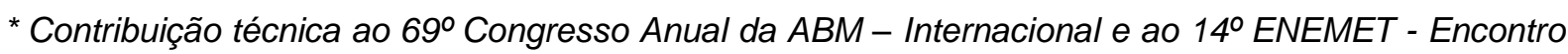
Nacional de Estudantes de Engenharia Metalúrgica, de Materiais e de Minas, 21 a 25 de julho de 2014, São Paulo, SP, Brasil.
} 


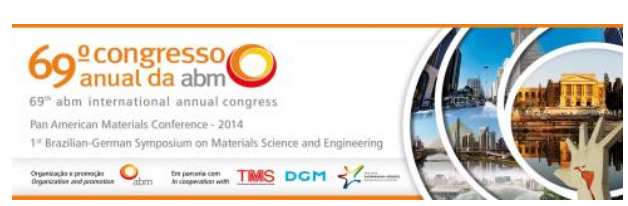

Tabela 5. Análise de riscos das soluções priorizadas

\begin{tabular}{|c|c|c|c|c|c|c|}
\hline \multirow{2}{*}{$\begin{array}{l}\text { Alto tempo } \\
\text { do Ensaio } \\
\text { Epstein }\end{array}$} & \multirow{2}{*}{$\begin{array}{c}\text { Otimização dos } \\
\text { ensaios de } \\
\text { Dureza e Tração }\end{array}$} & \multirow{2}{*}{$\begin{array}{l}\text { SOLUÇÃO } \\
\text { PRIORIZADA }\end{array}$} & \multirow{2}{*}{$\begin{array}{c}\text { Risco } \\
\text { Implement. }\end{array}$} & \multicolumn{2}{|c|}{$\begin{array}{l}\text { ANALISE DE } \\
\text { RISCO }\end{array}$} & \multirow{2}{*}{ Conting } \\
\hline & & & & Probabil. & Impacto & \\
\hline \multirow{7}{*}{ X } & \multirow{7}{*}{ X } & $\begin{array}{l}\text { Eleger um responsável na GLP para monitorar o material fins } \\
\text { elétricos }\end{array}$ & Não & - & - & - \\
\hline & & $\begin{array}{l}\text { Avaliar a disponibilidade do transporte de amostras (se atende } \\
\text { outros setores) }\end{array}$ & Não & - & - & - \\
\hline & & $\begin{array}{l}\text { Criar check list para monitoramento dos tempos dos ensaios } \\
\text { envolvendo os aços fins elétricos }\end{array}$ & Não & - & - & - \\
\hline & & $\begin{array}{l}\text { Definir um horário limite para coleta das amostra (a serem } \\
\text { enviadas à GGDP) }\end{array}$ & Não & - & - & - \\
\hline & & $\begin{array}{l}\text { Criar indicador de medição do lead time real semanalmente e } \\
\text { mensalmente }\end{array}$ & Não & - & - & - \\
\hline & & Criar indicador de material aguardando ensaio & Não & - & - & - \\
\hline & & $\begin{array}{l}\text { Liberar material aguardando ensaio de Epstein antes do final do } \\
\text { ensaio (apenas no final do mês) }\end{array}$ & $\begin{array}{l}\text { Material aprovado com valores } \\
\text { podendo afetar o cliente }\end{array}$ & Média & Baixo & $\begin{array}{l}\text { Liberar mat. } \\
\text { pelo ensaio } \\
\text { de dureza }\end{array}$ \\
\hline & \multirow{4}{*}{ x } & Estudar as normas de garantias, MPA e padrões internos & Não & - & - & - \\
\hline & & Consultar clientes quanto à necessidade de ensaio de tração & Não & - & - & - \\
\hline & & $\begin{array}{l}\text { Conhecer qual o tipo de ensaio/processo o material é } \\
\text { submetido nos clientes }\end{array}$ & Não & - & - & - \\
\hline & & Eliminar ensaios de tração para clientes que não solicitem & Reclamação de cliente. & Pequena & Média & \begin{tabular}{|c|} 
Aplicar \\
ação após \\
OK do \\
cliente. \\
\end{tabular} \\
\hline & \multirow{5}{*}{ X } & $\begin{array}{l}\text { Fazer levantamento de dados para análise de dureza LM, CE e } \\
\text { LO }\end{array}$ & Não & - & - & - \\
\hline & & Estudar as normas de garantias, MPA e padrões internos & Não & - & - & - \\
\hline & & Consultar clientes quanto à necessidade de ensaio de dureza & Não & - & - & - \\
\hline & & $\begin{array}{l}\text { Conhecer qual o tipo de ensaio/processo o material é } \\
\text { submetido nos clientes }\end{array}$ & Não & - & - & - \\
\hline & & $\begin{array}{l}\text { Passar a usar dureza apenas do região do centro (CE) da } \\
\text { bobina }\end{array}$ & Não & - & - & - \\
\hline
\end{tabular}

Tabela 6. Implementação das aç DETALHAMENTO DO PLANO DE AÇ̃̃o PARA IIPPLEMENTAÇÃO EM LARGA ESCALA

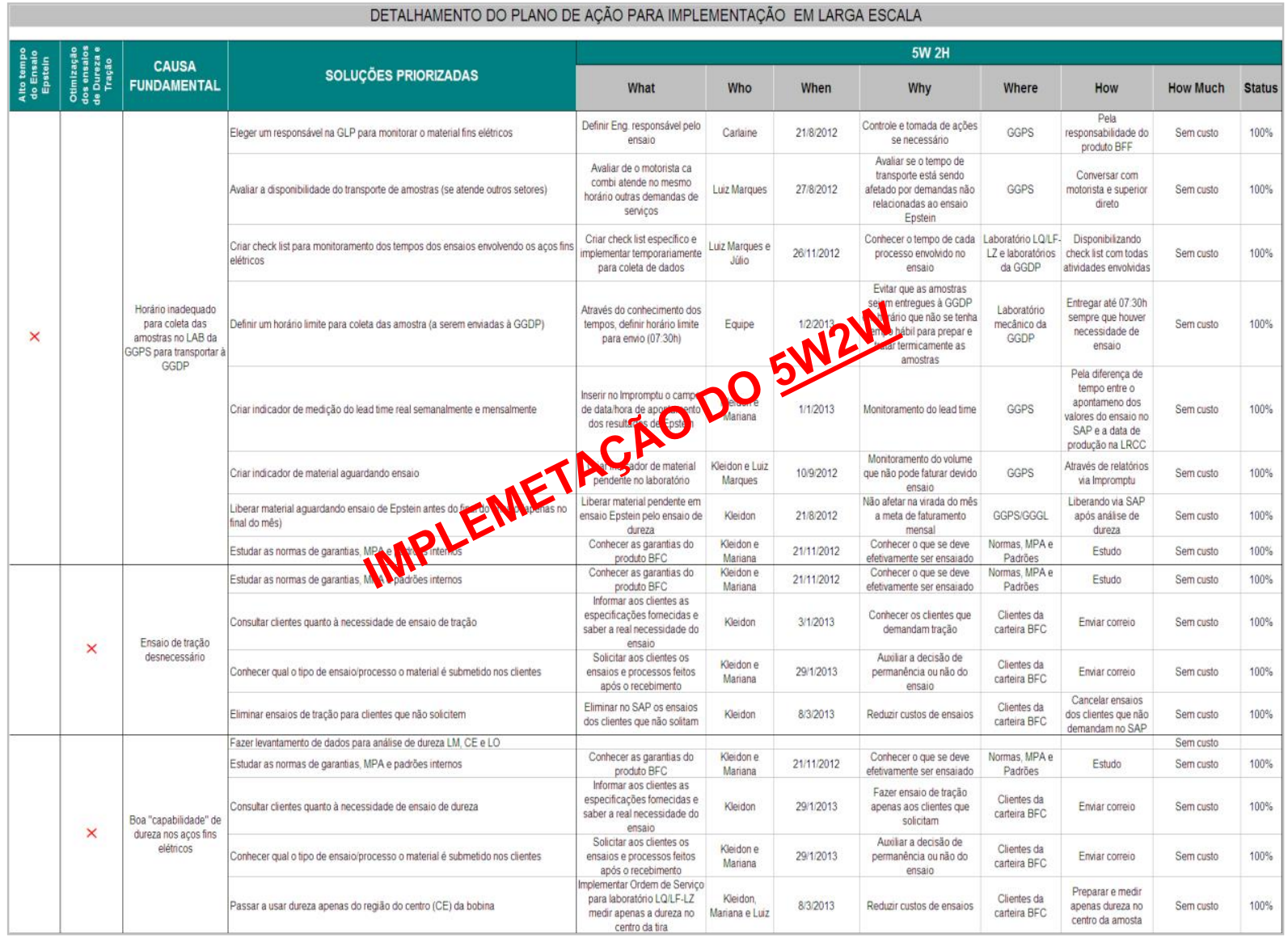

\footnotetext{
* Contribuição técnica ao 69ํㅡㄹ Congresso Anual da ABM - Internacional e ao 14ํㅡㄹ ENEMET - Encontro Nacional de Estudantes de Engenharia Metalúrgica, de Materiais e de Minas, 21 a 25 de julho de 2014, São Paulo, SP, Brasil.
} 

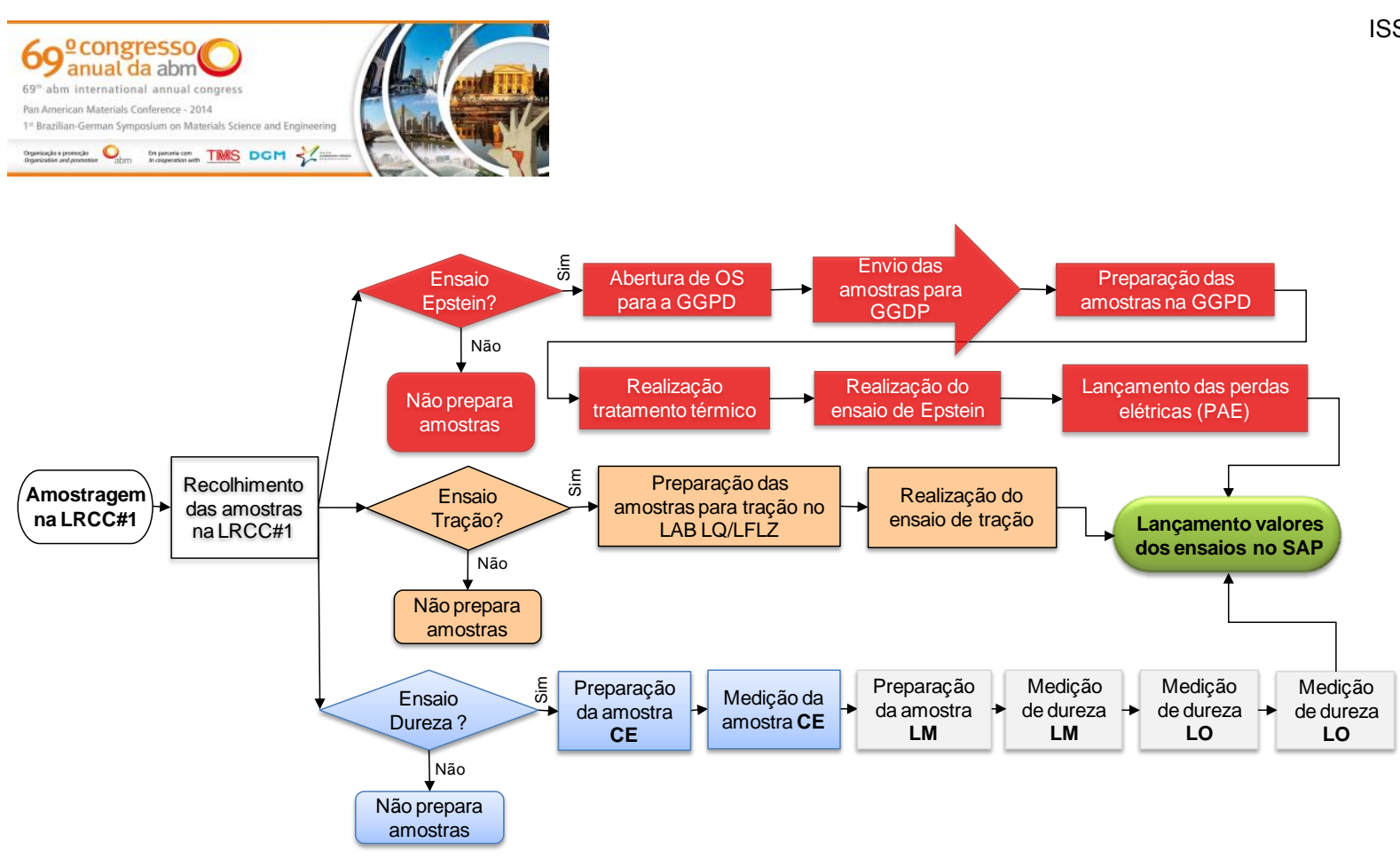

Figura 13. Mapa de Processos dos ensaios dos produtos fins elétricos (após revisão)

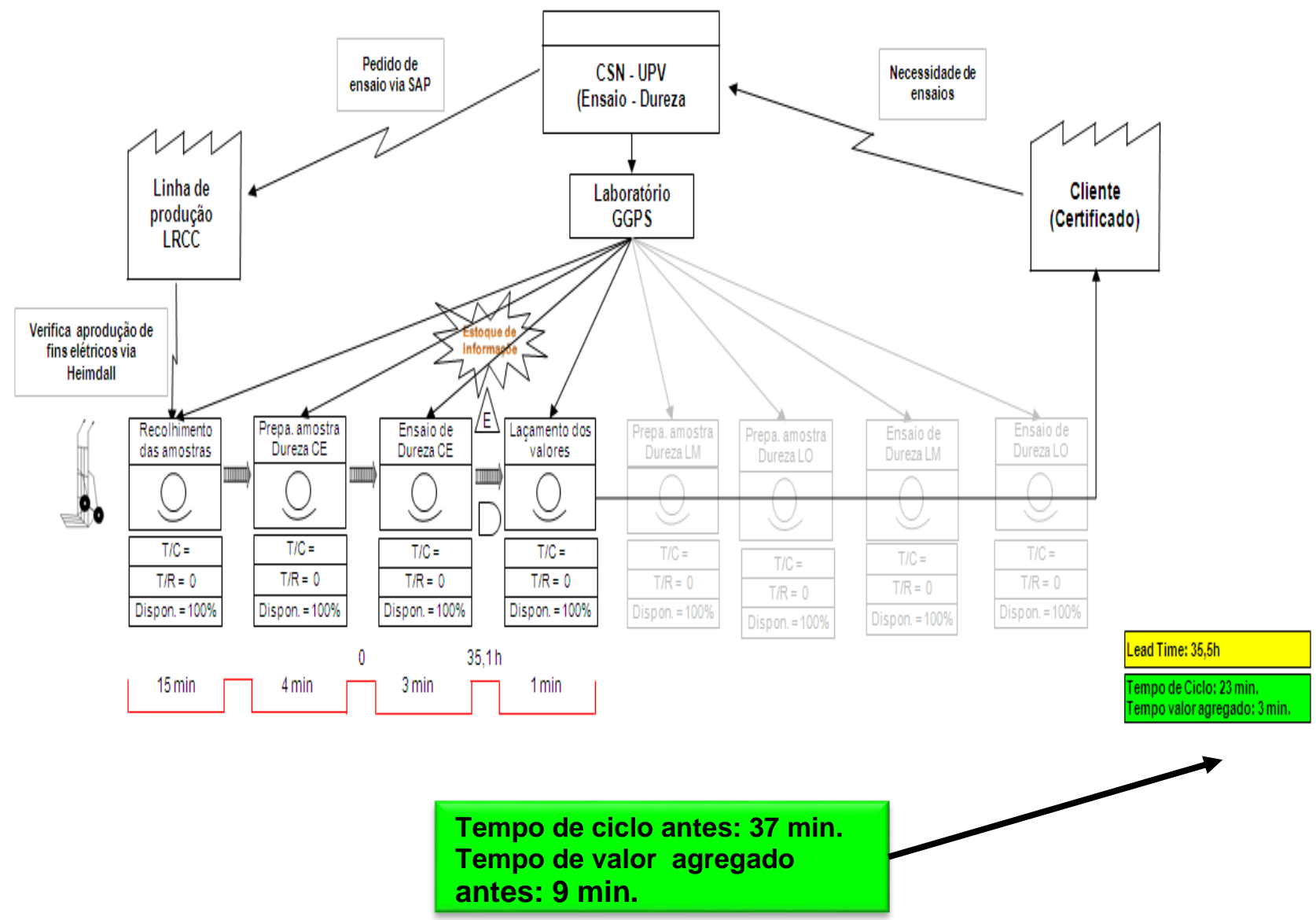

Figura 14. Mapa de Fluxo de Valor do ensaio de dureza (após revisão)

Conforme pode ser observado na figura 14, o ensaio de dureza passou a ser realizado com apenas quatro operações. Houve uma redução de $50 \%$ no número de atividades envolvidas nesta análise. O tempo do ciclo para medição da dureza antes era de 37 minutos, com 9 minutos de valor agregado. Após a alteração, o tempo de ciclo passou para 23 minutos, representando uma redução de $38 \%$. O tempo de

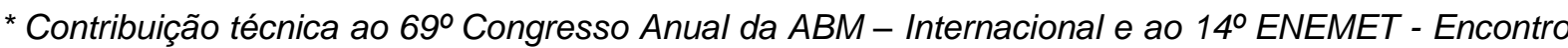
Nacional de Estudantes de Engenharia Metalúrgica, de Materiais e de Minas, 21 a 25 de julho de 2014, São Paulo, SP, Brasil.
} 


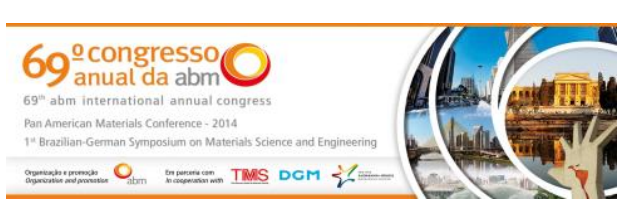

valor agregado passou a ser de 3 minutos, mostrando uma redução de $67 \%$ em relação aos 9 minutos anteriormente.

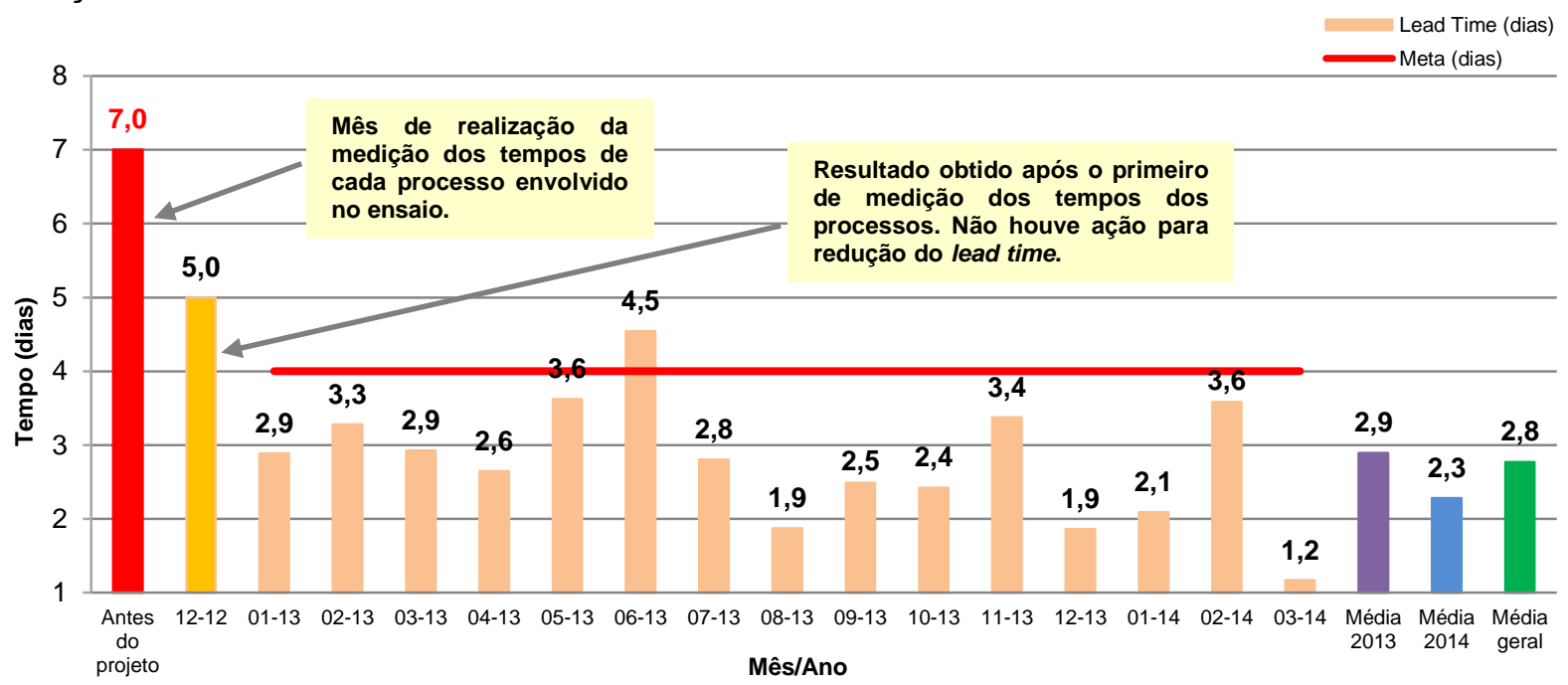

Figura 15. Lead Time do ensaio epstein do produto para fins elétricos

A figura 15 mostra o ganho obtido com a redução do Lead Time do ensaio de epstein. Antes do projeto, o tempo médio para a realização deste ensaio era 7 dias, com a implementação das ações, este indicador reduziu para 2,8 dias, representando uma redução de $60 \%$. Ao se comparar o desempenho médio de 2014 (2,3 dias) ao valor de Antes do Projeto (7 dias), a redução é de 67\%.

Os ganhos mensuráveis deste projeto podem ser vistos na tabela 7 a seguir.

Tabela 7. Ganhos tangíveis (mensuráveis) do projeto

\begin{tabular}{|c|c|c|c|c|c|c|c|c|}
\hline \multirow{3}{*}{ Ensaios } & \multicolumn{4}{|c|}{ Lead time } & \multicolumn{4}{|c|}{ Quantidade de ensaios } \\
\hline & \multirow{2}{*}{ Antes } & \multirow{2}{*}{ Depois } & \multicolumn{2}{|c|}{ Redução } & \multirow{2}{*}{ Antes } & \multirow{2}{*}{ Depois } & \multicolumn{2}{|c|}{ Redução } \\
\hline & & & Tempo & Percentual & & & Quantidade & Percentual \\
\hline Epstein & $168 \mathrm{~h}$ & $67,2 \mathrm{~h}$ & $48 \mathrm{~h}$ & $60 \%$ & 88 & 18 & 70 & $80 \%$ \\
\hline Dureza & $37 \mathrm{~min}$. & $23 \mathrm{~min}$. & $14 \mathrm{~min}$. & $38 \%$ & 551 & 182 & 369 & $67 \%$ \\
\hline Tração & - & - & - & - & 183 & 37 & 146 & $80 \%$ \\
\hline
\end{tabular}

Além da redução no Lead Time mostrado no gráfico (figura 15), é possível perceber outros ganhos mencionados na tabela 7, como a redução na quantidade dos ensaios, sendo $80 \%$ a menos nos ensaios de epstein, $67 \%$ para os ensaios de dureza e $80 \%$ para os ensaios de tração.

Outros ganhos obtidos com este trabalho são descritos a seguir:

- Liberação para faturamento no mesmo dia de produção em $80 \%$ da produção;

- Menor geração de amostras para ensaio (maior rendimento de massa);

- Menor exposição dos operadores ao risco de acidente (corte com amostras);

- Otimização da mão dos laboratórios usada nos ensaios;

- Menor consumo dos insumos: gás e energia elétrica.

\section{CONCLUSÃO}

O emprego dos conceitos da produção enxuta em ensaios de liberação dos produtos para fins elétricos na siderurgia mostrou a eficácia dos princípios dessa filosofia de

\footnotetext{
* Contribuição técnica ao 69ำ Congresso Anual da ABM - Internacional e ao 14ํㅡㄹ ENEMET - Encontro Nacional de Estudantes de Engenharia Metalúrgica, de Materiais e de Minas, 21 a 25 de julho de 2014, São Paulo, SP, Brasil.
} 
produção. A eliminação de desperdícios pode e deve ser um processo contínuo em qualquer empresa.

Com o uso de métodos e ferramentas adequadas, foi possível superar os objetivos e metas estabelecidas. Com a redução de $60 \%$ do Lead Time do ensaio de epstein, superou-se em duas vezes a meta de $30 \%$ inicialmente definida, além de diminuir em 38\% o Lead Time do ensaio de dureza.

Ainda foi possível reduzir em $80 \%$ a quantidade de ensaio epstein, diminuir $67 \%$ dos ensaios de dureza e $80 \%$ os ensaios de tração.

Os resultados obtidos permitiram liberar para entrega/faturamento $80 \%$ da produção no mesmo dia de produção na linha de Recozimento Contínuo, agilizando a entrega de pros acabados.

A quantidade de ensaio mantida foi suficiente para garantirmos os ensaios acordados com os clientes.

\section{Agradecimentos}

Agradecemos a colaboração com auxílio técnico e execução deste projeto:

- Evaldo Guimarães Teixeira, Técnico de Desenvolvimento, Gerência Geral de Desenvolvimento de Produtos, Companhia Siderúrgica Nacional;

- Ranieri Corrêa Salazar, Engenheiro de Produção, Gerência de Recozimento e Acabamento, Companhia Siderúrgica Nacional;

- Equipes do Laboratório de Qualidade de Produtos Laminados, Gerência Geral de Desenvolvimento de Produtos, Companhia Siderúrgica Nacional;

- Equipes do Laboratório do Centro de Pesquisa, Gerência Geral de Desenvolvimento de Produtos, Companhia Siderúrgica Nacional.

\section{BIBLIOGRAFIA}

1 Pande PS, Neuman RP, Cavanagh RR. The Six Sigma Way - How GE, Motorola and Other Top Companies Are Honing Their Performance. New York: McGraw-Hill; 2000.

2 Werkema MCC. Ferramentas estatísticas básicas para o gerenciamento de processos. $1^{\text {a }}$ ed. Werkema Editora; 1995.

3 Britz G, Emerling D, Hare L, Hoerl R, Shade J. How to teach others to apply statistical thinking. Quality Progress. 1997;June:67-79.

$4 \quad$ Harry MJ, Lawson JR. Six sigma producibility analysis and process characterization. Reading, Massachusetts: Addison -Wesley Publishing Company, 1992. 161p

5 Harry M. Basic six sigma concepts. Schaumburg: Motorola University Press; 1992.

6 Coleman J, Ross B, Sanders D. The Process Map. New York: Quality Engeneering; 1999.

7 Corrêa HL, Gianesi IGN, Caon M. Planejamento, programação e controle da produção: MRP II/ERP: conceitos, uso e implantação. 4를 ed. São Paulo: Atlas; 2001.

8 Werkema MCC. As ferramentas da qualidade no gerenciamento de processos. Belo Horizonte: Editora de Desenvolvimento Gerencial; 1995.

9 Mendes FB. Análise de Medidas de Perdas Magnéticas em Lâminas [Dissertação Mestre em Engenharia]. Florianópolis: Universidade Federal de Santa Catarina; 2004

10 Associação Brasileira de Normas Técnicas. NBR 6151: Produtos Laminados Planos de Aço Para Fins Elétricos - verificação das propriedades. Rio de Janeiro; 1996.

\footnotetext{
* Contribuição técnica ao $69^{\circ}$ Congresso Anual da ABM - Internacional e ao 14ํㅡㄹ ENEMET - Encontro Nacional de Estudantes de Engenharia Metalúrgica, de Materiais e de Minas, 21 a 25 de julho de 2014, São Paulo, SP, Brasil.
} 